\section{Commentary: Long journey and a heavy load}

\author{
Tomasz A. Timek, MD, PhD
}

The expert review written by Goodwin and Selzman ${ }^{1}$ is a timely and welcome reminder that ventricular unloading offers an important adjunct in the treatment of acute myocardial infarction. The authors do well to convey that myocardial injury is not only related to lack of oxygen delivery induced by coronary occlusion but also oxygen consumption, which can be reduced in a mechanically supported circulation. The equilibrium is thus tipped in favor of tissue viability through reduction of myocardial work. Cardiac surgeons understand this concept well, and we have been taught that the pump is your friend because it can extinguish the fire of acute myocardial decompensation and unload the ventricle. The authors concentrate on ventricular unloading in conjunction with percutaneous interventions, yet the concept should be extended to the surgical arena. Recent data from the Society of Thoracic Surgeons database supports this inclination. Acharya and colleagues $^{2}$ reported that coronary artery bypass grafting in the setting of cardiogenic shock was associated with $18.1 \%$ overall mortality and $10.3 \%, 18.6 \%$, and $53.3 \%$ mortality for urgent, emergent, and salvage operations, respectively. Patients with preoperative mechanical support (MCS) had mortality of $37.2 \%$, whereas those who required MCS intra- or postoperatively had a mortality of $58.4 \%$. Although the risk profiles of these patients were not equivalent, these data suggest that, as in the case of intra-aortic balloon pump placement, ${ }^{3}$ preoperative ventricular unloading may be associated with better outcomes. To this end, the authors report significant increase of preoperative MCS use in myocardial revascularization from $1.3 \%$ to $2.6 \%$ between

From the Division of Cardiothoracic Surgery, Spectrum Health, Grand Rapids, Mich. Disclosures: The author reported no conflicts of interest.

The Journal policy requires editors and reviewers to disclose conflicts of interest and to decline handling or reviewing manuscripts for which they may have a conflict of interest. The editors and reviewers of this article have no conflicts of interest.

Received for publication Aug 10, 2020; revisions received Aug 10, 2020; accepted for publication Aug 10, 2020; available ahead of print Aug 14, 2020.

Address for reprints: Tomasz A. Timek, MD, PhD, Division of Cardiothoracic Surgery, Spectrum Health, Michigan State University College of Human Medicine, 100 Michigan Ave, NE, Grand Rapids, MI 49503 (E-mail: tomasz.timek@ spectrumhealth.org).

J Thorac Cardiovasc Surg 2021;161:2054-5

$0022-5223 / \$ 36.00$

Copyright $($ C 2020 by The American Association for Thoracic Surgery

https://doi.org/10.1016/j.jtcvs.2020.08.020

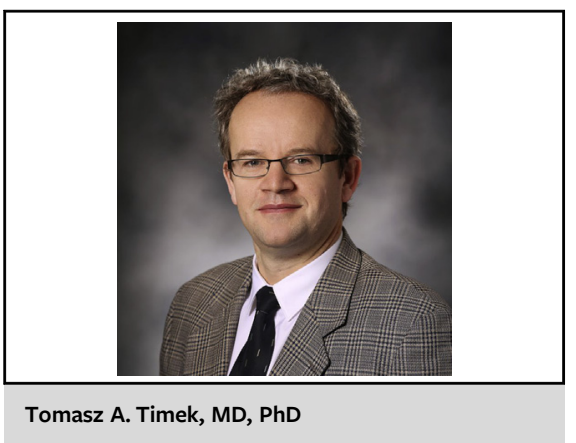

CENTRAL MESSAGE

Ventricular unloading should be considered along with revascu-

larization strategies in the treatment of acute myocardial infarction.

2011 and 2013. Salvage coronary artery bypass grafting may be an antiquated concept because an acutely ischemic and failing ventricle undergoes cardioplegic arrest and operative repair, thus receiving the knockout punch that is difficult to overcome in the postoperative phase. Catecholamines can be utilized to support the circulation, but the resultant increase in myocardial oxygen demand essentially equates to beating a tired horse to go uphill. Even in the setting of mechanically supported acutely ischemic pig hearts, catecholamine use to maintain perfusion pressure was associated with increased myocardial work. ${ }^{4}$ Extracorporeal membrane oxygenation (ECMO) has been increasingly used for circulatory assistance in the setting of cardiogenic shock, although ECMO support may not fully unload the heart. The Impella device (Danvers, Mass) unloads the left ventricle directly but may not provide adequate cardiac flow. Clinical data suggest equivalent outcomes in cardiogenic shock with both strategies, but in practice many patients are supported with both devices. ${ }^{5}$ Limited clinical data suggest that combination of ECMO and Impella may provide optimal reduction of left ventricle preload. ${ }^{6}$

Mechanical complications of myocardial infarction represent perhaps the greatest surgical challenge as myocardial dysfunction presents with concurrent valvular insufficiency or intracardiac shunts. Recently, Matteucis and colleagues $^{7}$ reported $37.3 \%$ survival to hospital discharge from the Extracorporeal Life Support Organization Registry in a cohort of 158 patients with mechanical complications of myocardial infarction supported with 
ECMO. It is noteworthy that $25.9 \%$ of these patients had cardiac arrest before initiation of circulatory support. We have treated patients with postinfarction ventricular septal defects using preoperative ECMO support and subsequent concurrent Impella decompression of the left ventricle to reduce stress on the repair. Although anecdotal, this experience may offer another treatment option. Metabolic abnormalities, pulmonary dysfunction, and renal insufficiency can be corrected while the heart is protected due to reduced oxygen demand. Few days may be needed to optimize the patient for the operating room, and we find that not infrequently this is safely achieved when the circulation is supported. Patients who continue to deteriorate declare themselves as nonsurgical, and good stewardship of available resources is maintained.

Harnessing ventricular unloading in the setting of myocardial ischemia compels a surgeon to refocus his or her attention on the supply/demand equilibrium of cardiac energetics. Clinical practice has been centered on supplying more oxygen through revascularization; yet, perhaps demanding less will yield improved outcomes because the road to recovery is often long and the load heavy.

\section{References}

1. Goodwin ML, Selzman GH. Take a load off: unloading and reperfusion. J Thorac Cardiovasc Surg. 2021;161:2046-50.

2. Acharya D, Gulack BC, Loyaga-Rendon RY, Davies JE, He X, Brennan JM et al. Clinical characteristics and outcomes of patients with myocardial infarction and cardiogenic shock undergoing coronary artery bypass surgery: data from the Society of Thoracic Surgeons national database. Ann Thorac Surg. 2016;101:558-66.

3. Pilarczyk K, Boening A, Jakob H, Langebartels G, Markewitz A, Haake N, et al Preoperative intra-aortic counterpulsation in high-risk patients undergoing cardiac surgery: a meta-analysis of randomized controlled trials. Eur J Cardiothorac Surg. 2016;49:5-17.

4. Udesen NLJ, Helgestad OKL, Banke ABS, Frederiksen PH, Josiassen J, Jensen LO, et al. Impact of concomitant vasoactive treatment and mechanical left ventricularunloading in a porcine model of profound cardiogenic shock. Crit Care. 2020;24:95.

5. Garan AR, Takeda K, Salna M, Vandenberge J, Doshi D, Karmpaliotis D, et al. Prospective comparison of a percutaneous ventricular assist device and venoarterial extracorporeal membrane oxygenation for patients with cardiogenic shock following acute myocardial infarction. J Am Heart Assoc. 2019;8: e012171.

6. Meuwese CL, Haan M, Zwetsloot PP, Braithwaite S, Ramjankhan F, van der Heijden J, et al. The hemodynamic effect of different left ventricular unloading techniques during veno-arterial extracorporeal life support: a systematic review and meta-analysis. Perfusion. January 17, 2020 [Epub ahead of print].

7. Matteucci M, Fina D, Jiritano F, Meani P, Raffa GR, Kowalewski M, et al. The use of extracorporeal membrane oxygenation in the setting of postinfarction mechanical complications: outcome analysis of the extracorporeal life support organization registry. Interact Cardiovasc Thorac Surg. 2020;31:369-74. 